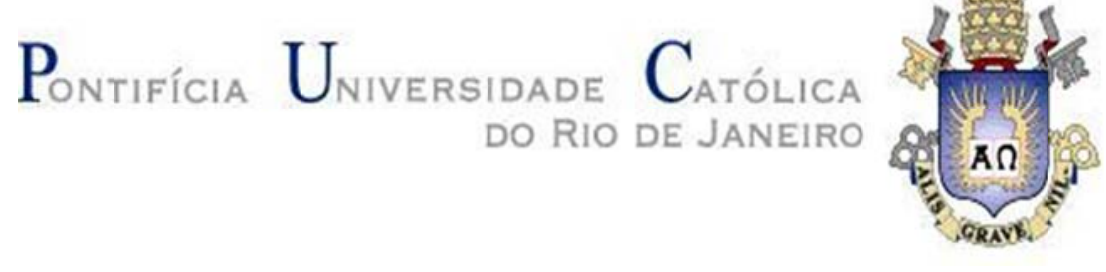

Daniela Gomes Schmidt

\title{
Avaliação estrutural de dois materiais compósitos após exposição a alta temperatura
}

Dissertação de Mestrado

Dissertação apresentada como requisito parcial para obtenção do grau de Mestre pelo Programa de Pósgraduação em Engenharia de Materiais e de Processos Químicos e Metalúrgicos do Departamento de Engenharia Química e de Materiais do Centro Técnico Científico da PUC-Rio.

Orientador: Prof. José Roberto Moraes d'Almeida 


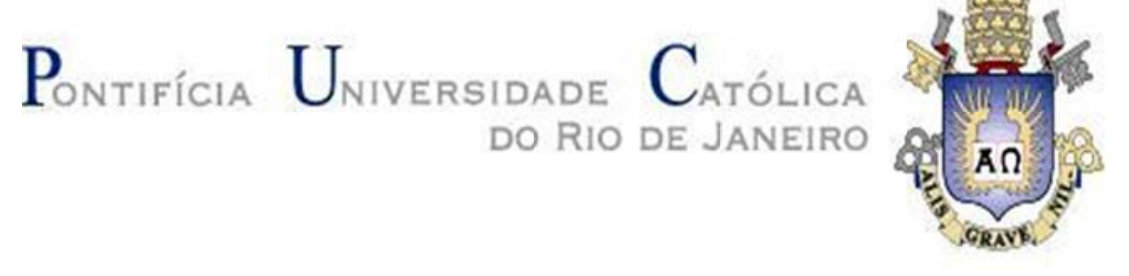

Daniela Gomes Schmidt

\begin{abstract}
Avaliação estrutural de dois materiais compósitos após exposição a alta temperatura
\end{abstract}

Dissertação apresentada como requisito parcial para obtenção do grau de Mestre pelo Programa de Pósgraduação em Engenharia de Materiais e de Processos Químicos e Metalúrgicos do Departamento de Engenharia Química e de Materiais do Centro Técnico Científico da PUC-Rio. Aprovada pela Comissão Examinadora abaixo assinada.

Prof. José Roberto Moraes d'Almeida Orientador e Presidente Departamento de Engenharia Química e de Materiais PUC Rio

Prof. Flávio de Andrade Silva Departamento de Engenharia Civil - PUC Rio

Dra. Nara Guidacci Berry Petrobras - CENPES

Prof. Márcio da Silveira Carvalho Coordenador Setorial de Pós-Graduação do Centro Técnico Científico da PUC-Rio

Rio de Janeiro, 22 de julho de 2016. 
Todos os direitos reservados. É proibida a reprodução total ou parcial do trabalho sem autorização da universidade, do autor e do orientador.

\section{Daniela Gomes Schmidt}

Graduada em Engenharia Mecânica pela Universidade Federal do Rio de Janeiro em 2003. Pós-graduação em Automação Industrial dos Sistemas de Produção, Refino e Transporte de Petróleo, pelo SENAI Rio, em 2005. Atuação profissional na área de óleo e gás como Engenheira de Equipamentos e na área de materiais não metálicos. Interesse em desenvolvimento com materiais compósitos de matriz polimérica.

Ficha Catalográfica

Schmidt, Daniela Gomes

Avaliação estrutural de dois materiais compósitos após exposição a alta temperatura / Daniela Gomes Schmidt ; orientador: José Roberto Moraes d'Almeida $-2016$.

203 f. : il. color. ; $30 \mathrm{~cm}$

Dissertação (mestrado)-Pontifícia Universidade Católica do Rio de Janeiro, Departamento de Engenharia de Materiais, 2016.

Inclui bibliografia

1. Engenharia de materiais - Teses. 2. Integridade mecânica. 3. Compósitos. 4. Resina fenólica. 5. Resina isoftálica. 6. Degradação térmica. I. D'Almeida, José Roberto Moraes. II. Pontifícia Universidade Católica do Rio de Janeiro. Departamento de Engenharia de Materiais. III. Título. 


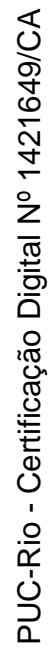

Aos meus filhos Marina e Pedro Luiz, pelo amor incondicional. 


\section{Agradecimentos}

A Deus, criador, que me deu forças para chegar até aqui.

Aos meus pais David e Soneli por todo amor e presença constante em todas as dificuldades e vitórias, primordiais para a formação de meu carácter.

À minha irmã Juliana pelo carinho e amizade.

Ao meu marido, Gustavo, pelo amor e compreensão em todos os momentos.

Aos meus filhos Marina e Pedro Luiz pelo amor e compreensão, mesmo privados de uma dedicação plena, pelos momentos em que tiveram que suportar minha ausência para que este trabalho pudesse ser realizado.

À minha tia Tanha e ao meu padrasto Luiz Fernando que sempre torceram por mim e ajudaram muito com as crianças.

Ao meu orientador José Roberto d'Almeida pela competente e constante orientação. Por todo o conhecimento e ensinamento compartilhado durante a elaboração desta dissertação. Pela serenidade e paciência.

Ao professor Marcos Henrique de Pinho Maurício e aluna de iniciação científica Luiza Gabriela pelo apoio técnico na realização das análises das microestruturas dos materiais, pelas técnicas de microscopia óptica e microscopia eletrônica de varredura.

À PETROBRAS e meus gestores, pela oportunidade de aprendizado contínuo e pela permissão concedida para que eu pudesse me dedicar à realização do meu mestrado.

Aos colegas do grupo de Especialistas em Materiais não Metálicos pelo incentivo, em especial ao Reuther pela motivação diária.

Ao Departamento de Engenharia de Materiais e de Processos Químicos e Metalúrgicos da PUC-Rio, docentes, colaboradores e técnicos de laboratório, em especial aos colegas Asafe, Max e Geovane que contribuíram para a realização deste trabalho.

Aos professores membros da banca examinadora por aceitarem prontamente o convite para avaliação deste trabalho e principalmente pelo conhecimento compartilhado. 


\section{Resumo}

Schmidt, Daniela Gomes; D’Almeida, José Roberto Moraes. Avaliação estrutural de dois materiais compósitos após exposição a alta temperatura. Rio de Janeiro, 2016. 203p. Dissertação de Mestrado Departamento de Engenharia de Materiais e Processos Químicos e Metalúrgicos, Pontifícia Universidade Católica do Rio de Janeiro.

A utilização de materiais compósitos de matriz polimérica em plataformas de petróleo é impulsionada pela necessidade de aumentar a vida útil dos componentes em ambientes corrosivos, contribuindo para uma menor demanda de manutenção e uma maior continuidade operacional. No entanto, estes materiais têm limitações quando são expostos a altas temperaturas e esta aplicação em navios e plataformas flutuantes está sujeita às regras das Sociedades Classificadoras. Um dos requisitos é a demonstração de que as grades em compósito retêm um nível significativo de integridade mecânica após exposição a temperaturas elevadas, típica de um incêndio. No Brasil, a aplicação de grades de piso em material compósito para plataformas de petróleo teve início em meados dos anos 90. Durante os primeiros anos, estas grades eram fornecidas com matriz de resina poliéster, pois, além de atender aos requisitos de desempenho da época, tinham um custo mais favorável. Atualmente, para convés aberto, onde pessoas podem permanecer como um refúgio seguro temporário ou estações de embarque de botes salva-vidas, os critérios de segurança das Sociedades Classificadoras são mais restritivos e apenas grades de piso em resina fenólica podem ser utilizadas. Este estudo tem como objetivo avaliar o comportamento mecânico de dois materiais compósitos após exposição a uma temperatura de $250^{\circ} \mathrm{C}$. O primeiro material consiste de um compósito de matriz poliéster isoftálica e o segundo de resina fenólica, ambos reforçados com fibra de vidro. Análise termogravimétrica foi aplicada para avaliar a estabilidade térmica dos s materiais. As microestruturas foram caracterizadas pelas técnicas de microscopia óptica e microscopia eletrônica de varredura. Corpos de provas dos materiais como recebido e após degradação térmica foram submetidos a ensaios de flexão em três pontos.

\section{Palavras chave}

Integridade mecânica; compósitos; resina fenólica; resina isoftálica; degradação térmica. 


\section{Abstract}

Schmidt, Daniela Gomes; D’Almeida, José Roberto (Advisor). Structural evaluation of two composite materials submitted to high temperature. Rio de Janeiro, 2016. 203p. MSc Dissertation - Departamento de Engenharia de Materiais e Processos Químicos e Metalúrgicos, Pontifícia Universidade Católica do Rio de Janeiro.

The use of non-metallic composites floor gratings in offshore platforms is driven by the need of increased component life in corrosive environments. As a result, these floor gratings contribute to a lower demand of maintenance and greater operational continuity. However, these composite materials have limitations when are exposed to high temperatures. The application of these floor gratings on ships and floating offshore platforms is subject to the acceptance of Classification Societies rules. One of the requirements is to demonstrate that the gratings retain a significant level of mechanical integrity during and after a high temperature exposure, as a fire scenario. In Brazil, in the mid-90s, polyester resin was chosen as matrix for composite floor gratings. Nowadays, for open decks on oil exploration platforms where groups of people are likely to assemble such as temporary safe refuge or lifeboat embarkation area, due to more restrictive safety criteria as smoke density, gas toxicity and mechanical integrity in fires, only phenolic-based gratings are acceptable. This study aims to evaluate and compare the mechanical behavior of two composite materials after being exposed to a thermal degradation. One material consists of an isophthalic polyester resin and the other of a phenolic resin. Thermogravimetric analysis was applied to evaluate the thermal stability of materials. Evaluation of flexural mechanical properties of these composites, as received and after being exposed to $250^{\circ} \mathrm{C}$, were performed. The microstructures of the two polymeric glass fiber-reinforced composites were characterized using optical microscopy and also by scanning electron microscopy.

\section{Keywords}

Mechanical integrity; composites; phenolic resin; isophthalic resin; thermal degradation. 


\section{Sumário}

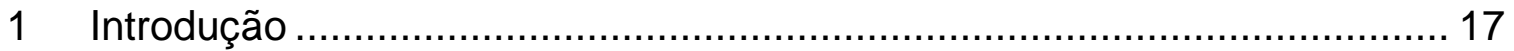

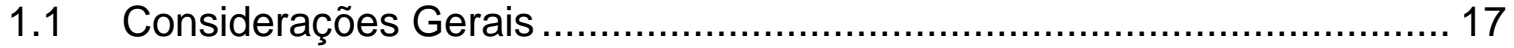

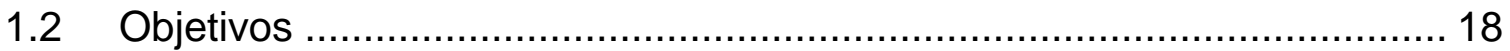

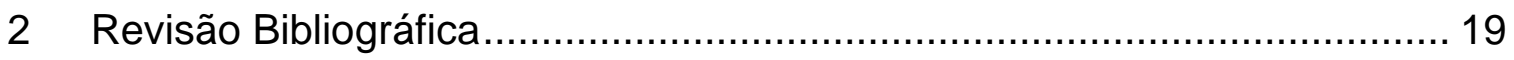



2.2 Aplicações de materiais compósitos em Unidades Estacionárias de

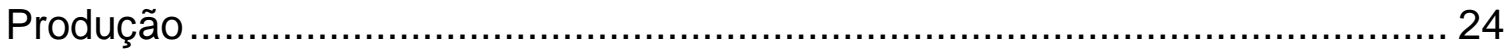

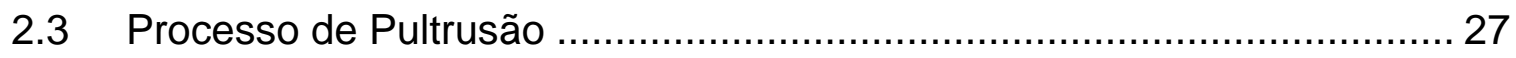

2.4 Compósitos de resina polimérica obtidos pelo processo de pultrusão ..... 29



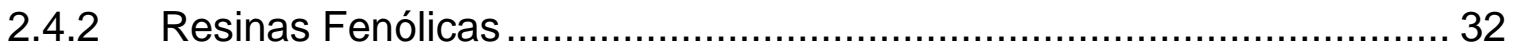

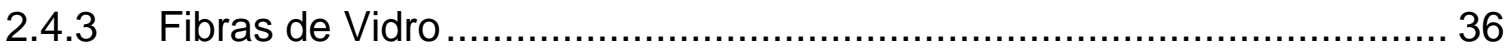

3 Comportamento dos materiais compósitos em exposição a altas

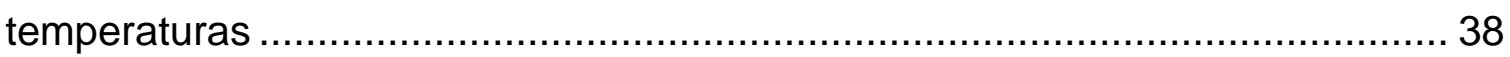

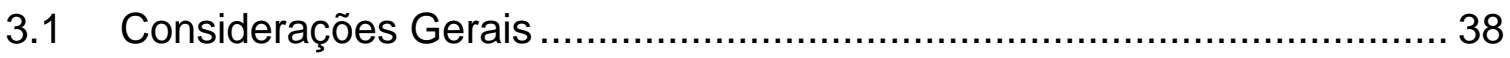

3.2 Decomposição térmica de polímeros e compósitos de matriz

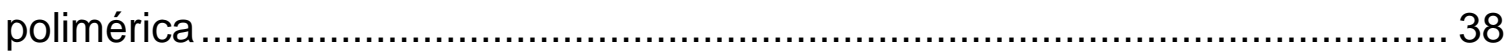

3.2.1 Decomposição térmica de resinas poliésteres ................................... 41

3.2.2 Decomposição térmica de resinas fenólicas ....................................... 42

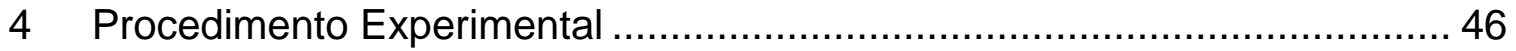

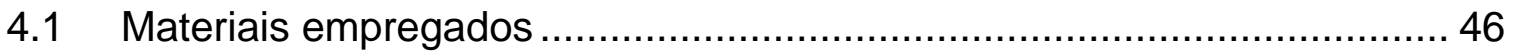

4.2 Análise Termogravimétrica ............................................................ 47

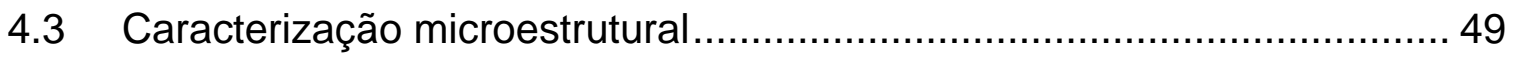

4.4 Ensaio de Flexão em três pontos para avaliação dos materiais pela



4.5 Ensaio de exposição dos materiais a alta temperatura …………............ 56



5.1 Análise Termogravimétrica dos materiais estudados ............................. 59



5.3 Análise micromecânica pela regra das misturas ...................................... 73 
5.4 Resultados e análises dos ensaios de flexão sem degradação

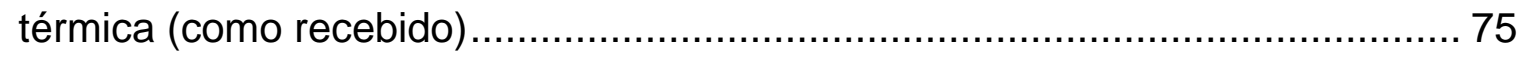

5.5 Comparação dos resultados da análise micromecânica com os



5.6 Resultados do ensaio de degradação térmica........................................ 85

5.7 Resultados e análises dos ensaios de flexão após degradação

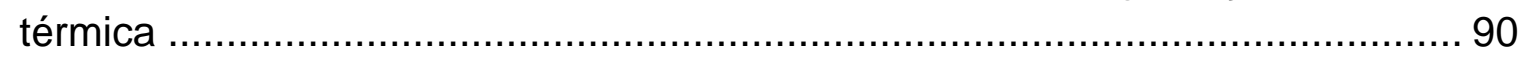

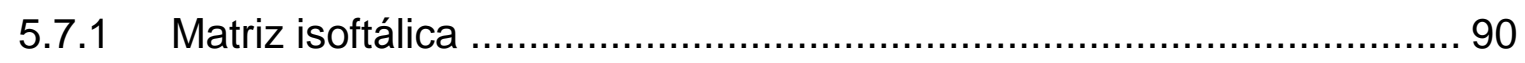

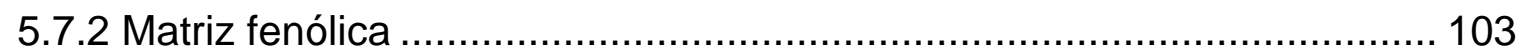

5.8 Comparação entre os resultados do estudo para os compósitos de

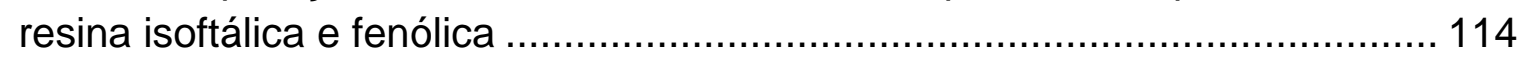

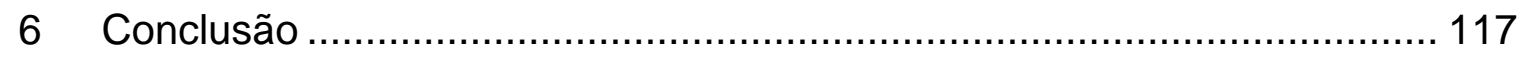

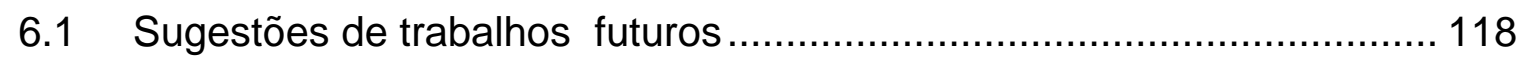

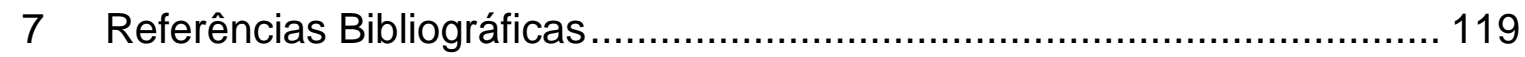

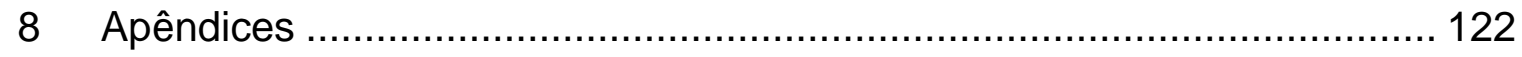




\section{Lista de Figuras}

Figura 1- Importância relativa dos materiais ao longo da história (Fonte:

STAAB, 1999).

Figura 2 - Classificação de materiais compósitos quanto ao tipo de reforço (FONTE: adaptado de CALLISTER, 2007).

Figura 3 - Representação esquemática do comportamento de um material isotrópico (a) e de um material anisotrópico (b). (Fonte: STABB, 1999).

Figura 4 - Exemplos de utilização de material compósito em instalações marítimas de produção de petróleo (Fonte: acervo pessoal).

Figura 5 - Grades de piso montada com perfis pultrudados confeccionada com resina fenólica (cortesia STRATUS).

Figura 6 - Esquema do processo de fabricação por pultrusão (FONTE: adaptado de página eletrônica STRONGWELL).

Figura 7 - Esquema de um perfil pultrudado (FONTE: adaptado de página eletrônica STRONGWELL).

Figura 8 - Poliéster insaturado.

Figura 9 - Grupo funcional do fenol (FONTE: elaborado pela autora).

Figura 10 - Polimerização do Fenol e formação das resinas novolaca e resol (FONTE: Revista Virtual de Química, volume 7).

Figura 11 - Esquema simplificado de produção da resina fenólica (adaptado de LEITE, 2002).

Figura 12 - Ciclo de combustão de materiais poliméricos (FONTE: adaptado de MOURITZ e GIBSON, 2006).

Figura 13 - Curvas da análise termogravimétrica para resina poliéster. 1.

Ortoftálica; 2. Isoftálica; 3. Halogenada (ácido HET); 4. Estervinílica e 5.

Bisfenol A (Fonte: adaptado de MOURITZ e GIBSON, 2006).

Figura 14 - Variação da resistência a tração, compressão e flexão da resina fenólica em função da temperatura (FONTE: BORGES, 2004).

Figura 15 - Comparação entre a densidade óptica da fumaça para as resinas fenólica, epóxi e poliéster em função do tempo (FONTE:

BORGES, 2004).

Figura 16 - Curva de análise termogravimétrica para um compósito de resina fenólica reforçado com fibra de vidro (FONTE: adaptado de MOURITZ e GIBSON, 2006).

Figura 17 - Perfil I em resina isoftálica reforçada com fibra de vidro. 
Figura 18 - Perfil quadrado em resina isoftálica reforçada com fibra de vidro.

Figura 19 - Perfil I em resina fenólica reforçada com fibra de vidro.

Figura 20 - Equipamento para análise termogravimétrica.

Figura 21 - Politriz automática para polimento das amostras.

Figura 22 - Amostras de compósitos em resina isoftálica (a) e resina fenólica (b) para microscopia

Figura 23 - Microscópio Óptico (a) e Microscópio Eletrônico de Varredura

(b) utilizados na análise das microscopias.

Figura 24 - Dispositivo para ensaio de flexão a três pontos do Laboratório de Microcaracterização de Materiais.

Figura 25 - Dispositivo para ensaio de flexão em três pontos do Laboratório de Estruturas e Materiais da Civil.

Figura 26 - Desenho esquemático da aplicação da carga no ensaio de flexão em três pontos.

Figura 27 - Forno mufla para ensaio de exposição à alta temperatura. .58

Figura 28 - TGA e DTG da resina isoftálica sem reforço.

Figura 29- Comparação entre as curvas obtidas nos ensaios TGA para compósitos de resina isoftálica e fenólica.

Figura 30 - Imagem do compósito de resina poliéster isoftálica capturada por microscópio óptico com lente de $20 \mathrm{X}$.

Figura 31 - Imagem do compósito de resina fenólica capturada por microscópio óptico com lente de $20 \mathrm{X}$

Figura 32 - Composição de algumas imagens do composto de resina isoftálica capturadas por MEV.

Figura 33 - Imagem de microscopia eletrônica de varredura do compósito de resina isoftálica com identificação de pontos para análise dos elementos constituintes.

Figura 34 - Elementos constituintes do ponto 1 da Figura 33 - aditivo anti chama.

Figura 35 - Elementos constituintes do ponto 3 da Figura 33 - matriz isoftálica.

Figura 36 - Elementos constituintes do ponto 5 da Figura 33 - fibra de vidro.

Figura 37 - Composição de algumas imagens do composto de resina fenólica capturadas por MEV. 
Figura 38 - Imagem de microscopia eletrônica de varredura do compósito de resina fenólica com identificação de pontos para análise dos elementos constituintes

Figura 39 - Elementos constituintes do ponto 1 da Figura 36 - fibra de vidro.

Figura 40 - Elementos constituintes do ponto 2 da Figura - matriz fenólica.

Figura 41 - Curvas Tensão-Deformação para o compósito de resina isoftálica sem degradação térmica (como recebido).

Figura 42 - Curvas Tensão-Deformação para o compósito de resina fenólica sem degradação térmica (como recebido).

Figura 43 - Energias de iniciação para os compósitos de resina isoftálica (como recebido).

Figura 44 - Energias de iniciação para os compósitos de resina fenólica (como recebido).

Figura 45 - Copos de Prova de compósito em resina isoftálica após ensaio de flexão em três pontos, mostrando ruptura por tração da camada mais externa do material.

Figura 46 - Corpos de prova de compósito em resina fenólica após ensaio de flexão em três pontos.

Figura 47- Detalhe das delaminações ocorridas nos corpos de prova do compósito em resina fenólica após ensaio de flexão em três pontos.

Figura 48 - Corpos de prova de compósitos de matriz isoftálica após ensaio de exposição a $250^{\circ} \mathrm{C}$ por 30 minutos.

Figura 49 - Corpos de prova de compósitos de matriz isoftálica após ensaio de exposição a $250^{\circ} \mathrm{C}$ por 60 minutos.

Figura 50 - Corpos de prova de compósitos de matriz isoftálica após ensaio de exposição a $250^{\circ} \mathrm{C}$ por 90 minutos.

Figura 51 - Corpos de prova de compósitos de matriz isoftálica após ensaio de exposição a $250^{\circ} \mathrm{C}$ por 120 minutos.

Figura 52 - Corpos de prova de compósitos de matriz fenólica após ensaio de exposição a $250{ }^{\circ} \mathrm{C}$ por 30 minutos.

Figura 53 - Corpos de prova de compósitos de matriz fenólica após ensaio de exposição a $250{ }^{\circ} \mathrm{C}$ por 60 minutos.

Figura 54 - Corpos de prova de compósitos de matriz fenólica após ensaio de exposição a $250{ }^{\circ} \mathrm{C}$ por 90 minutos.

Figura 55 - Corpos de prova de compósitos de matriz fenólica após ensaio de exposição a $250^{\circ} \mathrm{C}$ por 120 minutos. 
Figura 56 - Curva Tensão x Deformação para corpo de prova em compósito isoftálico com 30 minutos de exposição térmica a $250^{\circ} \mathrm{C}$.

Figura 57 - Detalhes do corpo de prova 04 de compósito isoftálico com 30 minutos de exposição a $250^{\circ} \mathrm{C}$.

Figura 58 - Curva Tensão x Deformação para corpo de prova em compósito isoftálico com 60 minutos de exposição térmica a $250{ }^{\circ} \mathrm{C}$.

Figura 59 - Detalhes do corpo de prova 02 de compósito isoftálico com 60 minutos de exposição térmica a $250^{\circ} \mathrm{C}$

Figura 60 - Curva Tensão x Deformação para corpo de prova em compósito isoftálico com 90 minutos de exposição térmica a $250{ }^{\circ} \mathrm{C}$.

Figura 61 - Detalhes do corpo de prova 02 de compósito isoftálico com 90 minutos de exposição térmica a $250^{\circ} \mathrm{C}$

Figura 62 - Curva Tensão x Deformação para corpo de prova em compósito isoftálico com 120 minutos de exposição térmica a $250^{\circ} \mathrm{C}$.

Figura 63 - Detalhes do corpo de prova 02 de compósito isoftálico com 120 minutos de exposição térmica a $250^{\circ} \mathrm{C}$

Figura 64 - Gráfico de caixa para os resultados de resistência à flexão para o compósito isoftálico antes e após exposição a $250^{\circ} \mathrm{C}$.

Figura 65 - Gráfico de caixa para os resultados de módulo tangente de flexão para o compósito isoftálico antes e após exposição a $250^{\circ} \mathrm{C}$. .96

Figura 66 - Gráfico de caixa para os resultados de deformação máxima para o compósito isoftálico antes e após exposição a $250^{\circ} \mathrm{C}$.

Figura 67 - Energia de iniciação para corpo de prova em compósito isoftálico com 30 minutos de exposição térmica a $250^{\circ} \mathrm{C}$

Figura 68 - Energia de iniciação para corpo de prova em compósito isoftálico com 60 minutos de exposição térmica a $250^{\circ} \mathrm{C}$

Figura 69 - Energia de Iniciação para corpo de prova em compósito isoftálico com 90 minutos de exposição térmica a $250^{\circ} \mathrm{C}$ 100

Figura 70 - Energia de iniciação para corpo de prova em compósito isoftálico com 120 minutos de exposição térmica a $250{ }^{\circ} \mathrm{C}$.

Figura 71 - Diagrama de caixa com representação da variação da energia total ou tenacidade dos corpos de prova de compósito isoftálico antes e após exposição a $250^{\circ} \mathrm{C}$

Figura 72 - Diagrama de caixa com representação da variação da energia de iniciação de defeitos macroscópicos dos corpos de prova de compósito isoftálico antes e após exposição a $250^{\circ} \mathrm{C}$. 
Figura 73 - Diagrama de caixa com representação da variação da energia de propagação de defeitos macroscópicos dos corpos de prova de compósito isoftálico antes e após exposição a $250^{\circ} \mathrm{C}$

Figura 74 - Curva Tensão x Deformação para corpo de prova em compósito fenólico com 30 minutos de exposição térmica a $250{ }^{\circ} \mathrm{C}$

Figura 75 - Detalhe do corpo de prova 01 de compósito fenólico com 30 minutos de exposição térmica a $250^{\circ} \mathrm{C}$. 104

Figura 76 - Curva Tensão x Deformação para corpo de prova em compósito fenólico com 60 minutos de exposição térmica a $250{ }^{\circ} \mathrm{C}$. 105

Figura 77 - Detalhe do corpo de prova 03 de compósito fenólico com 60 minutos de exposição térmica a $250^{\circ} \mathrm{C}$ 105

Figura 78 - Curva Tensão x Deformação para corpo de prova em compósito fenólico com 90 minutos de exposição térmica a $250{ }^{\circ} \mathrm{C}$ 106

Figura 79 - Detalhe do corpo de prova 04 de compósito fenólico com 90 minutos de exposição térmica a $250^{\circ}$. 106

Figura 80 - Curva Tensão x Deformação para corpo de prova em compósito fenólico com 120 minutos de exposição térmica a $250^{\circ} \mathrm{C}$

Figura 81 - Detalhe do corpo de prova 04 de compósito fenólico com 120 minutos de exposição térmica a $250^{\circ} \mathrm{C}$

Figura 82 - Gráfico de caixa para os resultados de resistência à flexão para o compósito fenólico antes e após exposição a $250{ }^{\circ} \mathrm{C}$.

Figura 83 - Gráfico de caixa para os resultados de resistência à flexão para o compósito fenólico antes e após exposição a $250{ }^{\circ} \mathrm{C}$.

Figura 84 - Gráfico de caixa para os resultados para deformação máxima à flexão para o compósito fenólico antes e após exposição a $250^{\circ} \mathrm{C}$

Figura 85 - - Energia de iniciação para corpo de prova em compósito fenólico com 30 minutos de exposição térmica a $250^{\circ} \mathrm{C}$.

Figura 86 - Energia de iniciação para corpo de prova em compósito fenólico com 60 minutos de exposição térmica a $250^{\circ} \mathrm{C}$.

Figura 87 - Energia de iniciação para corpo de prova em compósito fenólico com 90 minutos de exposição térmica a $250^{\circ} \mathrm{C}$.

Figura 88 - Energia de iniciação para corpo de prova em compósito fenólico com 120 minutos de exposição térmica a $250^{\circ} \mathrm{C}$.

Figura 89- Gráfico de caixa para os resultados de Energia Total (tenacidade) para o compósito fenólico antes e após exposição a $250{ }^{\circ} \mathrm{C}$. 
Figura 90 - Gráfico de caixa para os resultados de Energia de iniciação de defeitos macroscópicos dos corpos de prova de compósito fenólico antes e após exposição a $250^{\circ} \mathrm{C}$.

Figura 91 - Gráfico de caixa para os resultados de Energia de propagação de defeitos macroscópicos dos corpos de prova de o compósito fenólico antes e após exposição a $250^{\circ} \mathrm{C}$. 


\section{Lista de Tabelas}

Tabela 1 - Propriedades da resina poliéster (FONTE: CHACÓN, 2008). ..............32

Tabela 2 - Propriedades Resina Fenólica pura (MILANESE ET al, 2012)............36

Tabela 3 - Propriedades mecânicas da fibra de vidro tipo E (FONTE:

CHACÓN, 2008).

Tabela 4 - Composição aproximada da fibra de vidro tipo E (FONTE:

CHACÓN, 2008).

Tabela 5 - Resultados da TGA para o compósito de resina isoftálica...................60

Tabela 6 - Resultados da TGA para o compósito de resina fenólica.....................60

Tabela 7 - Percentual de área dos componentes do material compósito de resina isoftálica.

Tabela 8 - Percentual de área dos componentes do material compósito de resina fenólica.

Tabela 9 - Resumo dos módulos dos componentes e respectivas frações volumétricas

Tabela 10 - Resumo das propriedades mecânicas obtidas para o compósito de resina isoftálica.

Tabela 11 - Resumo das propriedades mecânicas obtidas para o compósito de resina fenólica.

Tabela 12 - Comparação dos resultados para o compósito de resina isoftálica (Fonte: PEPPER, 2012)......

Tabela 13 - Comparação dos resultados para o compósito de resina fenólica (Fonte: MICHELENA et al, 2013).

Tabela 14 - Resumo com os resultados médios dos ensaios de flexão para o compósito de resina isoftálica.

Tabela 15 - Resumo com os resultados médios dos ensaios de flexão para o compósito de resina fenólica. 